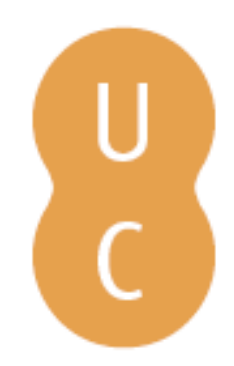

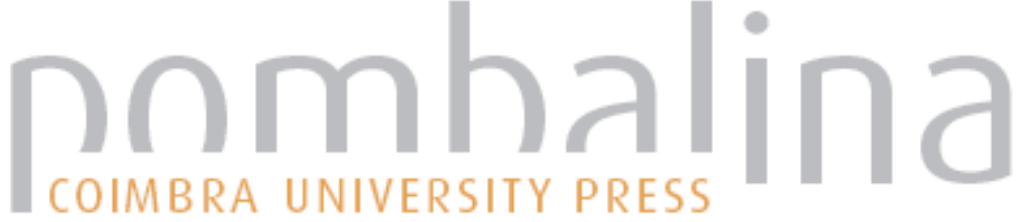

Em trânsito: do romance ao romance?

Autor(es): $\quad$ Arnaut, Ana Paula

Publicado por: Imprensa da Universidade de Coimbra

URL

persistente: URI:http://hdl.handle.net/10316.2/39260

DOI: $\quad$ DOI:http://dx.doi.org/10.14195/978-989-26-1229-4_18

Accessed : $\quad$ 26-Apr-2023 13:07:42

A navegação consulta e descarregamento dos títulos inseridos nas Bibliotecas Digitais UC Digitalis, UC Pombalina e UC Impactum, pressupõem a aceitação plena e sem reservas dos Termos e Condições de Uso destas Bibliotecas Digitais, disponíveis em https://digitalis.uc.pt/pt-pt/termos.

Conforme exposto nos referidos Termos e Condições de Uso, o descarregamento de títulos de acesso restrito requer uma licença válida de autorização devendo o utilizador aceder ao(s) documento(s) a partir de um endereço de IP da instituição detentora da supramencionada licença.

Ao utilizador é apenas permitido o descarregamento para uso pessoal, pelo que o emprego do(s) título(s) descarregado(s) para outro fim, designadamente comercial, carece de autorização do respetivo autor ou editor da obra.

Na medida em que todas as obras da UC Digitalis se encontram protegidas pelo Código do Direito de Autor e Direitos Conexos e demais legislação aplicável, toda a cópia, parcial ou total, deste documento, nos casos em que é legalmente admitida, deverá conter ou fazer-se acompanhar por este aviso.

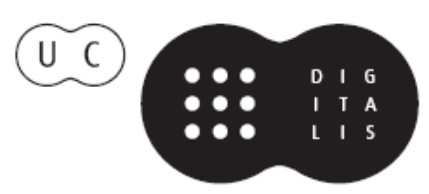


FRANCISCO DE OLIVEIRA

PAOLO FEDELI

DELFIM LEÃO

Coordenadores

\section{- ROMANCE ANTIGO ORIGENS DE UM GÉNERO LITERÁRIO}

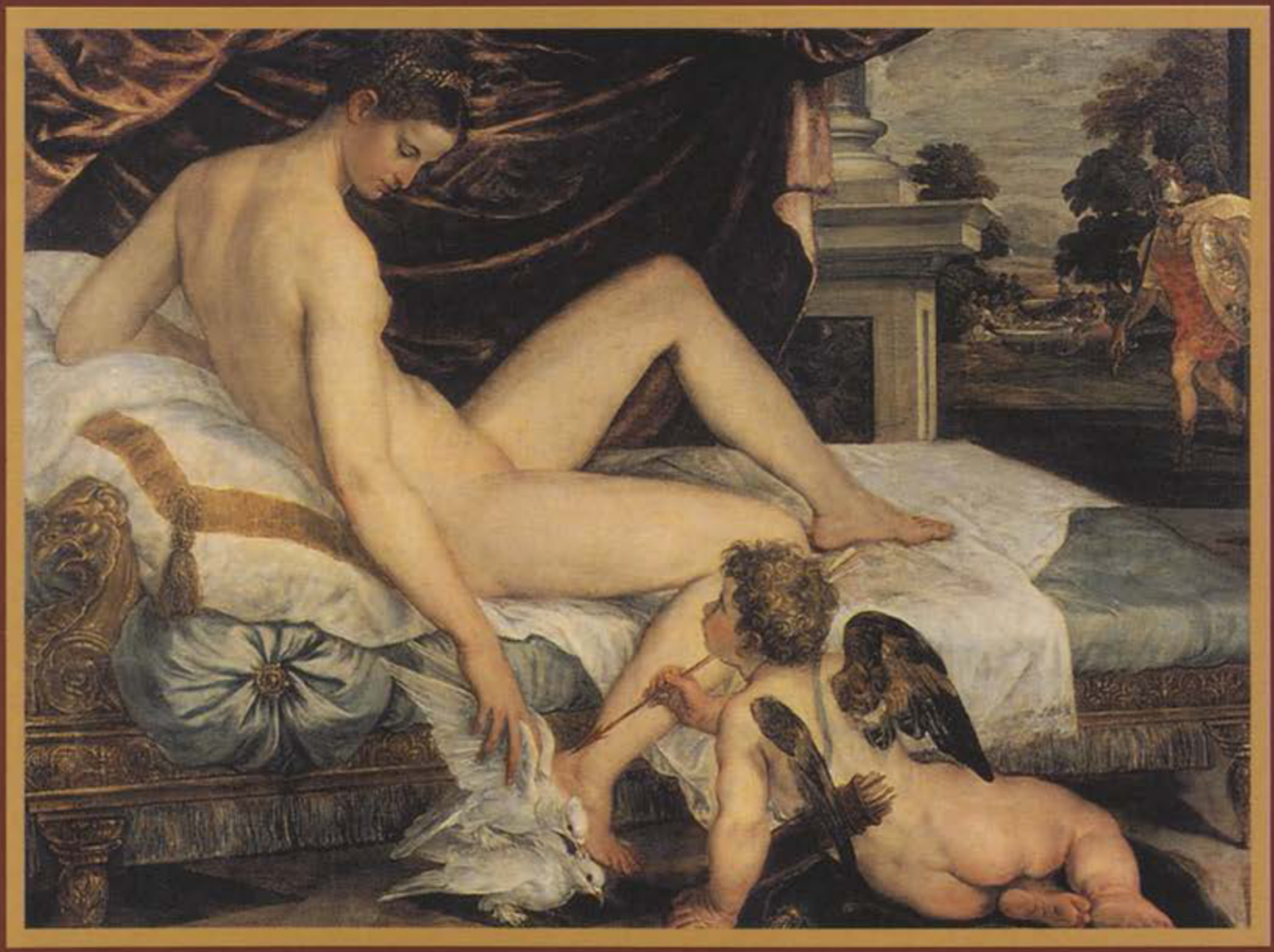

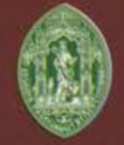

Universidade de Coimbra

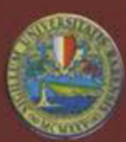

Università degli Studi di Bari

COIMBRA

2005 


\title{
EM TRÂNSITO: DO ROMANCE AO ROMANCE?
}

\author{
ANA PAULA ARNAUT \\ Universidade de Coimbra
}

A nudez talha no ar / os seus vestidos. António Franco Alexandre

O problema que hoje se põe em relação às raízes greco-latinas do género romance, ou, no mesmo âmbito, em relação à possível existência de romances nos primeiros séculos da nossa era, parece-nos encontrar equivalência na discussão que tem vindo a ocupar-se, desde tempos não muito remotos, da problemática da morte deste género literário.

Esta questão, que começa a ser expressa com maior veemência a partir do início da segunda década do século XX, por autores como T.S. Eliot e Ortega y Gasset, parece constituir uma espécie de mote que, segundo John Hollowell (1977:6-7), se intensifica no passado mais próximo da década de sessenta, principalmente a partir de posições críticas tomadas por autores como Leslie Fiedler (1964:173) ou, de forma mais modalizada, por John Barth (1967:32-33). Assim acontece porque, na verdade, se toma como ponto de partida e também de comparação o romance de canónica linhagem, cristalizado no panorama literário/genológico pelas obras de oitocentos (Rubin Jr.,1967:5; Martin, 1986:15).

Com efeito, no passado recente dos anos vinte (ainda de ousadia modernista) e, de forma ainda mais concreta, dos anos sessenta (os do início do controverso Post-Modernismo), como no passado distante da Antiguidade Clássica, entra em cena um conjunto de experimentações temáticas e formais que, de forma gradual mas cada vez mais intensa, se afasta dos usos e costumes literários vigentes, causando estranheza, instaurando resistência, gerando polémicas de índole diversa (respeitantes, não só mas também, à classificação genológica). 
No caso específico do Post-Modernismo, os diversos tipos de subversão e de ousadia estética (dos exercícios metaficcionais, desenvolvidos a partir de ocorrências incipientes em romances anteriores, à desagregação/fragmentação formal ou à mistura de géneros numa mesma obra, entre outras características) redundam numa deslegitimação do género romance (aqui entendido como uma das grandes narrativas $^{1}$ ) que, admitimos, pode, de facto, chocar algumas mentalidades mais adeptas das belles lettres tradicionais.

No que respeita à Antiguidade Clássica, o problema coloca-se não no que respeita à possível deslegitimação da ideia de romance, até porque esta designação não existia ainda (como, aliás, é referido por Ben Edwin Perry, 1967:4), mas, de modo bem mais englobante, no que se refere à fuga, ao desvio subversivo de uma tradição literária enraizada nos géneros então consagrados, como o épico ou o trágico.

Assim, se de alguma forma a mistura das várias linhas repristinatórias do romance post-modernista o colocam no domínio da paródia do romance canónico (desse modo levando a crer na morte do género), os textos de autores como Petrónio, Apuleio ou Cáriton - classificados por alguns como romance (Perry, 1967:4 e passim; Bakhtine, 1978:237 e passim) e, por outros, apenas como «narrativas de interesse literário» que não constituirão raiz de romance (Silva, 1974:8; Kristeva, 1979:16; Robert, 1972:11-12) - devem, pelas suas características, ser também incluídos no mesmo domínio da paródia, sim, mas da paródia dos géneros então conhecidos. Salvaguarde-se, a propósito, que, tal como Linda Hutcheon, entendemos que a carga semântica do termo 'paródia' deve alargar-se do intuito manifestamente cómico, veiculado por alguns dicionários, à hipótese de se referir a uma forma de imitação (de um texto, de um estilo de escola ou de um género literário), «but imitation characterized by ironic inversion, not always at the expense of the parodied text» (1985:6).

Por um lado, esta acepção aponta, tendencialmente, para uma diferença de entendimentos sobre a prática do presente e a de outrora, já que o que parece prevalecer em obras dos autores clássicos que acima mencionámos é, de facto, a primeira das acepções.

Por outro lado, no entanto - e como temos vindo a referir ainda de modo muito englobante -, a verdade é que começam a revelar-se

${ }^{1}$ Nestas, por extrapolação que consideramos lógica, incluímos o cânone do romance, em particular, e a literatura, ou pelo menos a ideia que dela costuma fazer-se, em geral. Veja-se, a propósito, A Condição Pós-Moderna de Jean-François Lyotard. 
algumas semelhanças entre a mais recente prática/moda literária e essa bem mais antiga produção narrativa.

Apesar disso, note-se, e tendo em conta a indelével multiplicidade de relações que o Post-Modernismo também receberá de variados estilos de outras épocas bem mais recentes (dando assim origem a uma espécie de efeito "manta de retalhos"), não nos parece pertinente definir, tout court - por considerarmos que esse seria um raciocínio relacional demasiado simplista, e também demasiado extenso e abrangente -, uma linha de enraizamento directa, linear e sistemática do romance post-modernista nesses textos que, por enquanto, na esteira de Aguiar e Silva, continuamos a apodar de «narrativas de interesse literário»".

Por conseguinte, julgamos necessário relativizar a ideia veiculada por William Spanos (1987:7-8), respeitante ao facto de ser incontornável a aceitação da existência de um notório impulso post-moderno ao longo de toda a história literária ocidental. De acordo com esta linha de raciocínio, esse impulso, reprimido e reprovado pelos guardiães da alta cultura, será também identificável em obras menos canónicas, ou melhor, menos canonizadas, de um leque de autores consagrados, que abrange, entre outros, os ancestrais Eurípedes (Orestes) e Petrónio (O Satyricon) ou (agora numa linha de influência mais afim ao Post-Modernismo) os mais recentes Cervantes (Don Quixote), Sterne (Tristram Shandy) ou Melville (Pierre).

Deste modo, como acima dissemos, apesar de concordarmos com a existência de um leque de semelhanças entre as características das obras mencionadas e a estética post-modernista, acreditamos que, no caso concreto dos autores clássicos, o impulso é ainda bastante incipiente, traduzindo-se mais num pré-impulso ou num embrião de impulso que, de facto, tendo em conta o efeito "manta de retalhos" da estética post-modernista, só poderá ser notório em obras de autores mais recentes. Em todo o caso, como veremos, este facto não derroga a hipótese de que algumas das características cultivadas pelos autores clássicos remetam, de forma mais ou menos clara, para uma tradição literária, ética e estética, de futuros paradigmas periodológicos, como o Romantismo, o Realismo-Naturalismo ou, até, o Post-Modernismo.

Por outras palavras: a provar-se este vínculo, não se invalida a ideia de que as mencionadas "narrativas de interesse literário» consubstanciarão, in germine, o ponto de partida de uma tradição genológica que, de facto, se alicerçará de forma coerente, coesa e canónica na mais recente modernidade dos séculos XVIII e XIX.

Vejamos, por exemplo, O Satyricon de Petrónio. 
Em primeiro lugar, como bem sublinha René Martin, e se atentarmos na acepção corrente de romance, «consistant à le definir comme étant une oeuvre de fiction (ce qui l'oppose à l'histoire), conçue néanmoins pour offrir l'apparence de la réalité (ce qui l'oppose au mythe et au conte), constituée par un récit (ce qui l'oppose au genre dramatique), écrite principalement en prose (ce qui l'oppose à l'épopée) et correspondant à une lecture d'assez longue durée (ce qui l'oppose à la nouvelle)» (1999:78-79), então é incontestável a inserção desta obra, como de outras a que faremos referência, no género em causa. Um género que, aduza-se à laia de parêntesis, antes de ter atingido a sua canonização, foi vilipendiado e condenado pelos mais diversos motivos: no mundo greco-romano, em data bem posterior à da publicação das primeiras obras, por ser considerado uma adaptação «to the taste and understanding of uncultivated or frivolous minded people» (Perry, 1967:5; cf. ibidem: 330,366); no século XVII, por ser considerado "como um perigoso elemento de perturbação passional e de corrupção dos bons costumes» (Silva, 1974:15).

Em segundo lugar, parece-nos ser notório que a semântica temática que aqui se expõe, bem como os condicionalismos e as influências quase determinísticas exercidas pelo meio sobre as personagens, são bastante semelhantes ao que será posteriormente equacionado e desenvolvido pelos realistas-naturalistas, epígonos incluídos.

Em terceiro lugar, mesmo que numa prática muito difusa, há a registar pelo menos uma linha de afinidade com a poética post-modernista. Deste modo, e apesar de o texto nos ter chegado incompleto, fragmentário, registe-se que as partes de que dispomos (sequenciais, muitas delas) parecem apontar para a ideia de que a fragmentação seria sempre, intrinsecamente, uma das principais características formais desta obra. Em consequência, ao invés de uma narrativa de traves mestras lineares, coesas e coerentes, como as que encontramos no panorama de oitocentos, salvo as excepções que sempre acontecem, são-nos oferecidos blocos-quadros narrativos que, à semelhança do que acontece em romances post-modernistas como $O$ Delfim de José Cardoso Pires (1968), podem consubstanciar um antepassado remoto de uma das formas de metaficção hoje muito praticada.

Referimo-nos, em concreto, à forma manifesta do modo linguístico, de acordo com designação de Linda Hutcheon, respeitante a textos em que a auto-consciência decorre não da exposição do nível semântico, mas da exposição do nível estrutural da obra. Nestes casos, o texto, evidenciando os blocos que o constituem, carece de uma canónica organização formal (princípio, meio e fim dados de forma plena, isto é, 
pormenorizada e sem grandes saltos entre os acontecimentos narrados). Como consequência desta (des)organização linguística, exige-se um maior esforço de leitura, concomitante a um maior empenho, e por conseguinte a uma maior participação, na decifração dos fios condutores que permitem fazer sentido do enunciado (Hutcheon, 1984: 8-29) ${ }^{2}$.

Este sentido, cuja construção nas obras em apreço anuncia o que futuramente ocorrerá nas (para a época) inovadoras Viagens na minha terra de Garrett (ou, de modo mais sistemático e transformado em metaficção, nas obras post-modernistas), é orientado por um narrador que, de quando em quando, dialoga com o leitor ou, simplesmente, chama a sua atenção para o que vai passar-se. Tal acontece de forma explícita em $O$ Asno de Ouro, quando o narrador se dirige abertamente ao leitor ${ }^{3}$ e, implicitamente, em Quéreas e Calirroe quando, numa

${ }^{2}$ Linda Hutcheon aponta, por um lado, as ficções conscientes do seu próprio processo narrativo e criativo e, por outro, aquelas que são linguisticamente auto-reflexivas. Dentro de cada um destes modos (o diegético e o linguístico) devem distinguir-se, pelo menos, duas formas ou variantes: a manifesta ("overt") e a dissimulada ("çovert"). No que respeita à forma manifesta do modo diegético, a auto-reflexão e a auto-consciência (que pode ser menos evidente na forma dissimulada, da qual pode até encontrar-se ausente) descortinam-se através de manifestações tematicamente explicitadas, por exemplo através de comentários que vão sendo tecidos (também alegórica e simbolicamente) sobre o próprio acto de escrita. Em relação às formas dissimuladas, a auto-reflexão é implícita e, no caso dos textos do modo diegético, ela manifesta-se através de modelos axiomaticamente incorporados que se prendem, entre outros, com as expectativas que determinados paradigmas literários criam no leitor. Estas expectativas remetem, por si só, para a ficcionalidade da obra (caso da indicação de género ou de subgénero) (pp.31-32). No caso do modo linguistico, e para além da forma manifesta a que fazemos referência no corpo do texto, há ainda a considerar a forma dissimulada, passivel de ser ilustrada e actualizada através desses casos extremos em que parece instaurar-se o caos linguístico. Tal acontece pela utilização de trocadilhos e por outros jogos de duplicidade semântica afins, num processo em que se nos afigura legítimo incluir os casos em que a linguagem parece ser exponencialmente gerada.

3 "Eis portanto a história do que me aconteceu na Grécia: preste atenção, leitor, porque ela lhe dará prazer" (p.12); "Mas talvez que o leitor escrupuloso, verificando esta parte da minha narrativa, me faça esta objecção: " - Como é possível, asno extravagante, que fechado no teu moinho, possas saber o que entretanto faziam, secretamente como afirmas, essas mulheres?»" (p.270); "Caro leitor, o que vai seguir-se não é um conto agradável, mas sim uma cena trágica, e nós tiramos o borzeguim para calçar o coturno..." (p.282); "Curioso leitor, talvez me pergunte com empenho o que foi dito, o que foi feito. Di-lo-ia, se tal fosse permitido, e o leitor ouvir-me-ia, se tal fosse possivel. Mas os seus ouvidos e a minha língua seriam igualmente culpados de tão temerária indiscrição. Todavia, não irritarei ainda mais uma curiosidade talvez santa; escute, e acredite em verdades." (p.341); "Eis o que vi; o leitor ouviu, e todavia não saberia compreender" (p.342). 
intervenção que manifesta o claro controlo que a entidade narrativa exerce sobre a narração dos acontecimentos (levado ao extremo pelos post-modernistas), se afirma que «O que aconteceu, vou dizê-lo mais adiante. Antes, porém, prefiro relatar o que, entretanto, se passou em Siracusa» (III.2.17).

A narrativa de Apuleio, O Asno de Ouro (também conhecido como "O Livro das Metamorfoses"), é ainda exemplar da linha paródica e subversiva - nem sempre cómica, lembramos - que tão bem caracterizará os romances post-modernistas. Veja-se, a propósito, como a transformação sofrida por Lucius, o protagonista, imitando embora a ideia englobante das metamorfoses relatadas por Ovídio na obra com o mesmo título, dela se afastam, no entanto, pela fuga subversiva e cómica ao tom sério, grave e pensado do autor (por exemplo no poema VIII, "Atlante convertido em monte"), isto é, pelo carácter risível e mirabolante da descrição das situações em que, já asno, Lucius se vê envolvido.

Veja-se ainda como, n'O Satyricon, o protagonista claramente compara a perseguição a que a cólera de Priapo o submete e a perseguição de Ulisses por Poseidon/Neptuno no final do Canto V da Odisseia. Citamos parte do fragmento em que se procede à referência explícita a este facto, tendo no entanto em conta que a relação paródica é passível de concretização/ilustração a partir de episódios imediatamente anteriores (relativos, por exemplo à menção aos açoites, pancadas e escarradelas infligidos pelos criados de Circe [2-5]):

Não é a mim apenas que a divindade e o Fado implacável perseguem. Já antes o herói de Tirinto, atormentado pela ira da senhora de Ínaco, teve de suportar o peso do céu; antes, o profano Laomedonte havia saciado já a cólera a duas divindades; Pélias sentiu o rancor de Juno; em sua inconsciência, Télefo foi pegar em armas e Ulisses teve medo perante os reinos de Neptuno. Também a mim, por terras afora e por águas do velho Nereu, me persegue a pesada ira de Priapo, senhor do Helesponto.

Agito com violência o meu leito, modelando-o como se fosse a imagem daquela que amo (139.2).

Sublinhe-se também como, em Quéreas e Calírroe, Cáriton imita, com o devido distanciamento, as aventuras e as figuras de grandes heróis épicos e/ou trágicos. No decorrer das diversas peripécias que envolvem a relação do par amoroso protagonista da narrativa, a personagem masculina é (pelo menos num primeiro grande momento) sujeita a pungentes descrições que, regra geral, descambam no cómico e na consequente desqualificação moral e psicológica. Em concomi- 
tância, desmitifica-se o conceito de herói, tal como Homero ou Virgílio o entendiam (como, aliás, já havia acontecido com Encólpio, protagonista de $O$ Satyricon). Sublinhemos, a propósito, que Mikhaïl Bakhtine, entre outros, apesar de reconhecer afinidades entre o género épico e o género romance, defende a ideia de que o último se formou, «précisément au cours du processus de destruction de la distance épique, de familiarisation comique du monde et de l'homme, d'abaissement de l'objet de la représentation artistique au niveau d'une réalité actuelle, fluide et inachevée» (1978:472).

Não por acaso, na cena que antecede o julgamento de Téron, acusado de ter raptado Calírroe, por exemplo, Quéreas surge não apenas vestido de negro e pálido, mas «enxovalhado, como no dia em que levou a mulher a sepultar» (III.4.4). Além disso, assolado pela dor e pelo sofrimento, Quéreas parece não ter qualquer capacidade para resistir às vicissitudes e aos problemas que vão surgindo, preferindo pedir ou tentar a morte a continuar a viver daquele modo. Assim acontece quando pensa ter matado a amada (I.5.1-7, I.6.1); quando, «dilacerado pelas súplicas dos pais» para que não partisse em busca de Calírroe, se atira «do navio à água, para se matar» (III.5.6-7); quando suplica a Mitridates que o devolva à cruz, depois de saber que Calírroe se havia casado com Dionísio de Mileto (IV.3.8-9); quando, em outras situações, pretende enforcar-se (V.10.7-10), ou quando se interroga sobre o que espera para se degolar (VII.1.6-7).

Ressalve-se, porém, que, em derradeira instância, é possível verificar uma alteração - diria mesmo uma evolução - no comportamento e nas atitudes desta personagem quando, entre outros casos, movida pelo desejo de vingança, comanda a armada egípcia contra Artaxerxes e o seu aliado Dionísio. Na guerra travada entre persas e egípcios revela coragem, sagacidade e estatura moral suficientes para adquirir a confiança dos soldados (VII.3.6-11) e para, de forma justa e humana, tomar resoluções sobre o destino de prisioneiros como Estatira, mulher do soberano persa a quem escreve palavras sábias e ponderadas:

$\mathrm{Tu}$ ias ser juiz no meu processo, mas eu antecipei-me a ganhar a causa diante do supremo juiz: pois é a guerra o melhor árbitro que existe, dos mais fortes e dos mais fracos. Foi ela que me devolveu Calírroe - e não foi só a minha mulher que me pôs nas mãos, como também a tua. Só que eu não imitei as tuas delongas, mas, acto continuo, mesmo sem a teres reclamado, devolvo-te Estatira, incólume e respeitada como uma rainha durante o cativeiro. Fica a saber que este presente te é mandado da parte de Calírroe, não da minha. Pedimos-te, em contrapartida, que te reconcilies com os Egípcios. É próprio de um rei, mais do que de qualquer outro, saber resignar-se. Terás nesses soldados homens de valor e amigos dedicados. Pois foi escolha deles, em vez de me acompanharem. permanecerem como amigos do teu lado (VIII.4.2-4). 
Decorre do exposto, como aliás também é possível observar a partir do percurso de aprendizagem moral e humana levado a cabo por Lucius em $O$ Asno de Ouro, que estas duas obras se consubstanciam em pré-texto do que será o romance de formação - o que, em séculos vindouros, narrará e analisará de forma mais detalhada, porque mais estruturada, o desenvolvimento espiritual, o desdobramento sentimental, a aprendizagem humana e social de um herói. Este será um adolescente ou um jovem adulto que, confrontando-se com o seu meio, vai aprendendo a conhecer-se a si mesmo e aos outros, vai gradualmente penetrando nos segredos e problemas da existência, haurindo nas suas experiências vitais a conformação do seu espírito e do seu carácter (Silva, 1974:68).

No caso do romance de Apuleio, Lucius, mais anti-herói do que herói, depois de se ter entregado aos mais diversos prazeres humanos e de, sem olhar às consequências, ter sido assolado pela fatal curiosidade que o transforma em asno (condição em que passa por uma série de provações, em concomitância com a manutenção do que o grande sacerdote classifica, quase no final, de «vergonhosos prazeres» - p.332), acaba por se entregar «com ardor ao serviço da deusa», aumentando, de dia para dia, o seu carácter religioso (p.338).

Caso ainda subsistam algumas dúvidas sobre a afinidade entre esta obra e o que será o futuro romance de formação, acreditamos que elas se dissiparão com a tomada de consciência de que a metadiegese, relativa à história de Amor e de Psiché, reduplica, salvaguardadas as devidas distâncias temáticas, um idêntico percurso de aprendizagem. Com efeito, não nos parece difícil estabelecer um paralelo formal entre as aventuras vividas pela personagem da diegese e essas outras vividas por Psiché. Em ambos os casos, pois, se aplica a embrionária fórmula conducente ao desenvolvimento humano: 'falta (curiosidade de Psiché que a leva a querer ver o rosto de Amor/curiosidade de Lucius em relação à prática da metamorfose) - castigo (Amor abandona Psiché/ Lucius é transformado em asno) - redenção (através das provas por que passam) - felicidade (banquete de núpcias/transformação em homem e ascese espiritual)' (Bakhtine, 1978:268).

Ainda a propósito do valor e da importância manifestadas por este romance e, no mesmo âmbito, por O Satyricon e por Quéreas e Calirroe, Mikhaïl Bakhtine sublinha outro tipo de interessantes ligações embrionárias que, no campo dos géneros, migrará da Antiguidade para a Modernidade (com as inevitáveis consequências para o Post-Modernismo). 
Desta feita, os romances latinos de Petrónio e de Apuleio são classificados como «roman[s] d'aventures et de moeurs» (Bakhtine, 1978:261), aos quais interessa, sobretudo, e ao contrário dos romances gregos, o homem e não a aç̧ão (ibidem:266). Os romances gregos como por exemplo o de Cáriton (considerado menos complexo do que os anteriores) - cabem, quase sempre, na designação extensional de «roman[s] d'aventures et d'épreuves» (ibidem:239). Nestes se apresentam diversos aspectos, já inscritos em outras matrizes genológicas da Antiguidade, que se prolongam, de forma diversa (paródica ou não), pelo romance de cavalaria da Idade Média, ou por obras posteriores que, entre outros, abarcam os períodos do Barroco e do Romantismo (ibidem: 241-257).

Se é certo que os três romances apresentados permitem ao autor russo delinear, de forma diversa, o enraizamento do futuro verdadeiro romance de aventuras moderno, não é menos certo que, para o mesmo autor, o texto de Apuleio faculta, ainda, a possibilidade de descortinar o embrião de, pelo menos, dois subgéneros: o romance picaresco (tendo em conta o cómico e o ridículo de muitas das situações apresentadas) e, numa leitura que, em nosso entender, é demasiada incipiente e parcamente justificada e ilustrada (todavia possível), o romance policial (tendo em conta a presença de elementos criminais em diversos momentos da obra) (ibidem:273).

Por seu turno, a semântica interna de $O$ Satyricon, relativa quer às aventuras das personagens quer ao facto de apresentar retalhos do quotidiano da época a que se reporta, coloca-o no limiar de um terceiro grupo de romances antigos: o biográfico. Assim, apesar de sublinhar que «l'Antiquité n'a produit ni un tel roman, ni une grande oeuvre biographique que nous pourrions nommer ainsi, par référence à notre terminologie», Bakhtine salvaguarda que «Elle a, néanmoins, élaboré toute une suite de formes autobiographiques et biographiques notables» que, à semelhança do que ocorre com outros veios genológicos, "ont exercé une influence énorme non seulement sur l'évolution des biographies et autobiographies européennes, mais sur tout le roman européen» (ibidem:278).

Em ambos os romances, acrescentamos nós, parece ainda inevitável e inegável a possibilidade de os lermos à luz do subgénero do romance erótico. Assim, sendo embora verdade que tal potencial se verifica mais em $O$ Satyricon do que em $O$ Asno de Ouro (referimo-nos, essencialmente, à matrona lasciva do livro $\mathrm{X}$ ), não é menos verdade que, em qualquer dos textos, como frisou Adriana Bebiano a propósito do primeiro, o amor que aqui se representa é «muito pouco 
espiritual, muito feito de desejo». Mais do que amor, é «uma força anárquica, que nenhuma Lei pode conter» e que, por conseguinte, «não aceita constrangimentos sociais» (2003:53).

Uma outra questão, que decorre do exposto nestes últimos parágrafos, começa a apontar para a existência de uma outra vertente relacional com romances posteriores. Com efeito, a hipótese levantada por Bakhtine, sobre a presença de diversos embriões de género nas obras referidas, parece-nos remeter também (embora de modo vago) para a futura problemática da fluidez genológica. Uma vertente já ensaiada no cenário da literatura nacional por Almeida Garrett e levada ao extremo pelo Post-Modernismo. Este, ao congregar, de forma ostensiva e nem sempre pacífica, múltiplas práticas (sub)genológicas e modais, instaura uma crise de classificação tipológica que não marca presença no romance de linhagem tradicional e canónica.

Para além disso, há ainda a salientar um outro aspecto: exige o cânone literário, pelo menos assim tem acontecido até ao presente, que a linguagem das belles-lettres se exerça de forma substancialmente diferente da linguagem do quotidiano. Autor que se preze deverá distinguir-se da banalidade, pela utilização de recursos e artifícios estilísticos não pouco sublimes. Mais uma vez, na prática recente do Post-Modernismo como na prática literária destes romances antigos, contesta-se o modo canónico de apresentação narrativa. Como consequência da diluição das barreiras que separam a linguagem da literatura da linguagem do quotidiano, surgem, inevitavelmente, as questões relacionadas com a validade literária das obras e, por extensão lógica, com a possibilidade de se considerar que o romance morreu ou, para o efeito, que o romance clássico não existiu.

De acordo com o ponto de vista exposto ao longo deste texto, torna-se evidente que os processos de codificação postos em prática nas narrativas-romances da Antiguidade greco-latina, a capacidade de representação do universo diegético e de modelização do real ou, na mesma linha de raciocínio, a capacidade de caracterização de personagens e de exposição-análise dos seus conflitos mais íntimos, bem como a potencialidade de representação ideológica, não atingem a complexidade que, no futuro, se nos oferecerá ler. Mas tal entendimento não implica, pelas relações que estabelecemos entre diversas práticas de diferentes épocas, que não possamos mudar a designação de «narrativas de interesse literário» para a classificação de romance. Se tomarmos como ponto de comparação o romance dos séculos XVIII e XIX, as narrativas antigas a que fizemos referência podem até parecer infantis. No entanto, adequando ao contexto algumas palavras de 
Vergílio Ferreira, o esforço feito «foi talvez necessário, inevitável. Não se é adulto sem se ser criança» (1982:195).

\section{BIBLIOGRAFIA}

APULEIO, Lúcio, O Asno de Ouro. ([Lisboa]: Amigos do Livro, ([1976?]).

CÁRITON, Quéreas e Calirroe (Trad., int. e notas de Maria de Fátima de Sousa e Silva, Lisboa, Edições Cosmos, 1996).

PETRÓNIO, O Satyricon (Trad. de Delfim Ferreira Leão - no prelo).

BARTH, John, "The Literature of Exhaustion", Atlantic, August (1967), 29-34.

BEBIANO, Adriana, "Shakespeare e os clássicos: metamorfoses e reescritas", Biblos (2003), 43-59.

FERREIRA, Vergilio, Conta-Corrente l ( $3^{3}$ ed., Lisboa, Bertrand, 1982).

FIEDLER, Leslie, Waiting for the End (New York Stein \& Day, 1964).

HOLLOWELL, John, Fact and Fiction. The New Journalism and the Nonfictional Novel (Chapel Hill, The University of North Carolina Press, 1977).

HUTCHEON, Linda, Narcissistic Narrative. The Metafictional Paradox (New York \& London, Methuen, 1984).

HUTCHEON, Linda, A Theory of Parody. The Teachings of Twentieth Century Art Forms (New York \& London, Methuen, 1985).

LYOTARD, Jean-François, A Condição Pós-Moderna (Trad. José Bragança de Miranda. Lisboa, Gradiva, s./d.)

MARTIN, René, Le Satyricon. Pétrone (Paris, Ellipses, 1999).

MARTIN, Wallace, Recent Theories of Narrative (Ithaca and London, Cornell University Press, 1986).

PERRY, Ben Edwin, The Ancient Romances (Berkeley and Los Angeles, University of California Press, 1967).

ROBERT, Marthe, Roman des origines et origines des romans (Paris, Bernard Gasset, 1972).

RUBIN Jr., Louis D., The Curious Death of the Novel: Essays in American Literature (Baton Rouge, Louisiana State University Press, 1967).

SPANOS, William, Repetitions. The Postmodern Occasion in Literature and Culture (Baton Rouge and London, Louisiana State University Press, 1987). 